\title{
The Urban Poor in Dhaka City : Their Struggles and Coping Strategies during the Floods
}

\author{
Sabina Rashid \\ Research Anthropologist
}

September 1998

Research and Evaluation and Division, BRAC

Dhaka, Bangladesh 


\title{
The Urban Poor in Dhaka City: their Struggles and Coping Strategies during the Floods
}

\begin{abstract}
Poorer groups are exposed to increased vulnerabilities during periods of floods. Some of the difficulties faced by them include loss of possessions, fears of extortion and looting, and separation from their social network. The poor undertake different coping strategies to adapt to the floods such as abandoning land or housing, salvaging household items, selling land or livestock, and moving housing or family members to safer places. Perceptions of loss of the poor seem to be far more affected by damages in personal livelihood, and less by the overall scale of losses in the area. Women and children are often the most vulnerable groups during such disasters. Lack of sanitation facilities affected women badly. A majority of the latrines were submerged and inaccessible. This resulted in loss of privacy and shame for the women, with most being forced to defecate in their own homes. Some women were able to access, with great difficulty, latrines outside their neighbouring area. Floods usually result in an acute scarcity of safe drinking water due to the contamination of water sources, such as tube-wells and reserve tanks. This adversely affects the existing poor health conditions of slum dwellers. There were numerous reports of diarrhoea and other illnesses amongst both children and adults. The floods left most of the urban poor unemployed. This resulted in an increase in tension and domestic violence, particularly towards women. In some areas, BRAC members were pressured into repaying loans even though most were severely affected by. the floods. Furthermore, NGOs chose to implement separate flood relief strategies instead of co-ordinating their efforts.
\end{abstract}




\section{Introduction}

Bangladesh recently experienced her most devastating flood in over a decade. The damage was significant. The capital city of Dhaka was particularly affected. During such times of crisis, normal life patterns are disrupted, and individuals and families are exposed to great material and personal losses. The poor undertook several different strategies to cope with the disaster. In addition, non-governmental organisations (NGOs) ${ }^{1}$ and government agencies mobilised resources for intervention in the flood hit areas, and food, medicine and clothing were provided for the poor.

A preliminary research study was undertaken in Dhaka to identify some of the problems and constraints faced by the urban poor living in the flood affected areas. The study documents the experiences of a large number of urban poor men and women living in several bastis (slums), and illustrates the complete devastation in their lives, from extensive losses in personal and material resources, to greater uncertainties with employment, health, and access to basic services. The study attempts to highlight some of the perceptions, needs and coping strategies of the urban poor during the floods.

Floods are recurring events in Bangladesh, and the experiences of the urban poor in a disaster situation needs attention. A better understanding of their experiences, practices and concerns is important. Thus, the study attempts to provide insights, allowing planners and policy makers to adequately assist in future floods.

\footnotetext{
${ }^{1}$ Hereafter referred to as NGOs.
} 


\section{Methodology}

This was a short qualitative study. Altogether thirty two men and women, BRAC and non-BRAC members, from four bastis (slums) were randomly selected and interviewed. The slums visited included Shaheedertek and Bailtola in Mohammedpur, Katashurberi slum, and Shibir Masjid and Mothertek in the Shobujbagh area,. Wherever possible, when discussing sensitive women's issues, the interviews took place in the privacy of one of the women's homes. This afforded them the privacy to speak freely about issues related to violence and sexual harassment occurring during the floods. However, as most slums were submerged by floodwaters, majority of the discussions took place on roadsides, boats, and at a shelter. The interviews were informal. Information was crosschecked through further discussions with other informants, NGO workers, and slum dwellers residing in the area. The length of the interviews varied from one to one and a half-hours.

\section{Limitations of the Study}

It was a short, exploratory study to initially assess the needs and perceptions of the urban poor during the floods. As such, it was not possible to explore in-depth some of the broader issues. The study sample was homogenous, based on the experiences of slum dwellers living in Dhaka City.

\section{Findings and Discussion}

\section{Homelessness : Increased Vulnerability of the Poor}

During the floods, poor people suffer from considerable vulnerability ranging from a loss in material resources, to fears of theft and extortion, to becoming separated from their wider social network $(1,2)$. Their narratives revealed a number of concerns. The women and men spoke of the fear of the rising levels of water, "the water rose and I was with two children, so I went and stayed at the medical college... My house is submerged, we sleep on the pakka rastha (main road)... what to do there is no where else to go for us?" 
Another woman exclaimed, "there is faeces floating around inside our homes... what will we do? We have to move!"

A few institutions provided temporary, shelters for the flood affected poor. Many of the poor had become displaced, and moved with their basic belongings of utensils and bedding to the nearby shelters and relief camps. A number of women mentioned a place which was primarily a hospital for the elderly, as their place of shelter for the past few weeks. They had previously stayed at the nearby Islamic Foundation building and in an empty construction site. Slum dwellers from similar neighbourhoods preferred to move to the same shelter. This ensured that the existing ties and social network at the slums remained intact in the unfamiliar shelter, providing strength and security for one another. A study showed similar behaviour where people who had become separated from their community were easily disadvantaged. Families displaced by floods tended to cluster together with their $\mathrm{kin}^{2}$ in their new settlement (3).

Others spoke of sleeping on the main road when they had no other alternatives. In several bastis, the poor had raised the level of their chowkis (beds) and stoves with bamboos and desperately attempted to keep their basic belongings afloat. In some of the houses, bricks were inserted under the chowki (bed) to raise it above water level, "we went and got eet (bricks) from the roadside and put it under our beds to remain afloat.." Cattle and goats were left in empty construction sites.

The most devastating loss for the poor was the irreparable damage done to their homes. For the urban poor, security is having a roof over their heads (4). The women and men repeatedly cried over the loss of their homes. A group of men remarked, "we have lost everything, without our homes we have nothing and now our houses are gone, broken and destroyed...." Their sense of despair and utter helplessness at their present situation was overwhelming.

\footnotetext{
2 Kin here refers to blood family members and fictive kin members.
} 
An important concern was the high incidence of theft occurring when families left their belongings and sought temporary shelter elsewhere. A family narrated, "when we went for shelter, our fans and other items such as clothing, utensils were all stolen. Pieces of our tin roof was taken." One woman exclaimed, "Apa, what are we going to do, sort out our utensils and belongings or buy food? All we have is our home and now we have nothing, no tin, no home, everything is flooded!" A woman sadly explained, "I stay awake all night to guard our household things now that our house is under water, the children sleep next to me." Several flood studies documenting people displaced by the floods found that slum dwellers do not re-locate too far from their original residing place. They preferred to remain close by, in the hope that the area will remain undamaged (2).

\section{Hygiene, Shame and the 'Public' Gaze}

During such disasters, women and children tend to be the most vulnerable (5). Most women did not have access to basic sanitation as majority of the latrines were submerged by flood waters. This resulted in women having to resort to desperate measures to cope with this predicament. Some women expressed their dismay at the situation, "Apa, what to do now we put our faeces in polythene packets or newspapers and throw it into the water and we have to do the same thing with our children's faeces..." Despite the more relaxed atmosphere of purda $h^{3}$ rules in urban areas, women experienced shame and felt uncomfortable using the few remaining latrines in the presence of 'unfamiliar' men who often loitered near by. Most of them mentioned being able to freely access latrines with greater privacy in the past. With the recent floods, however, the situation had become difficult, leaving women feeling vulnerable and exposed to the public domain of men (5). Some women resorted to going to other less flooded bastis and using their latrines. Others would control themselves for as long as possible, and finally if they had no choice, were forced to urinate or defecate inside their own homes. A few women spoke of the indignity of having to take baths on the roadside in public view. "All of us take baths together. We take turns taking a bath on the roadside. They see us but what else can we do?"

\footnotetext{
${ }^{3}$ Purdah has shifting meanings contextually and historically. Here I refer to the seclusion of women from the public world of men.
} 
Some of the men spoke with resignation of their own inadequacies at being unable to provide clothing for their wives, with their spouses 'indecently' exposed to the public gaze of male strangers. "Apa at least we as men can manage somehow, but what about the mother of our children? Now with the floods we cannot even-clothe them properly, and they have to go out into the open in their cheera (torn) saris! What will people say?" The urban men and women expressed their frustration at being unable to live in dignity as human beings. They were worried about breaking social norms, and this created tension for the families. Studies on Bengali society have found social norms to be flexible depending on circumstances, with people overlooking 'inappropriate' behaviour, and not making it a matter of shame for the family (6). A recent study, however, on adolescent girls' experiences during the recent floods, found that women and young girl's were subjected to disparaging comments from men if they were seen to be inappropriately dressed, despite the circumstances (5).

\section{No Safe Drinking Water : Diarrhea, Sickness and III health}

Floods usually result in an acute scarcity of safe drinking water due to the contamination of water sources such as tube-wells and reserve tanks. This adversely impacts the existing poor health conditions of the slum dwellers. Some women living in the Kata Shurberi bastis coped by purchasing water. "We buy water from the owner of the deep tube welldepending on the person it costs us 20 taka, 10 taka or 40 taka. "Not everyone, however, could afford to buy water, and basically resorted to drinking whatever dirty water was available. The common declaration was, "What to do, Apa?" People in the interviews complained of fevers and high temperatures. "Apa, my mother-in-law is so sick, because of all this dirty water she is nearly dying. " Another woman said, "my son is very sick, for the last few days he has dysentery and is very sick ...the NGO doctor gave us some tablets, but how can a child eat tablets we need syrup." Another woman piped up, 'they sell syrup in the market. Why do they give us tablets? Our children will not be able to swallow these big tablets? My husband is also very sick, he has loose motion and has been in bed for some days." 
In all of the areas visited, the men and women in the bastis kept saying, "give us medicine", "my son is sick", "my husband has had diarrhoea for two days", and in the areas visited by boat, most of the basti people desperately asked for saline (ORS). A few asked "Apa, do you have medicines?" Due to the flood, individuals and families living in slums and shelters were increasingly isolated from accessing adequate medical care and medicines.

\section{No Work : How Can We Repay Our Loans?}

During any disaster situation, work and wages become scarce for the poor. The prices of basic food items generally multiply, with severe stress imposed on the poor who are dependent on daily wages for survival. Most of the urban poor are unskilled, and involved in the informal sector. A majority tend to work in uncertain jobs as wage labourers and daily labourers. Thus, during the floods such jobs are most likely to be affected and threatened $(4,7)$. All of the women and men complained of the lack of work available, "My husband cannot ride a rickshaw, ${ }^{4}$ it costs 30 taka daily to rent but where will he go with it...there is flood, and there is no income." Another woman said, "my husband has been sleeping for two days, he has no work because he now only makes 20 taka a day riding a baby taxi..." A basti man commented, "well my mateer kaj (earth cutting) is completely finished - there is no work for me anymore." Another man said, "I used to drive the truck from here to collect sand and/or bricks and take it to Gulshan and Baridhara. I earned 150 to 200 taka a day...now I have no job and I am unemployed."

A woman and her mother, both of whom would break bricks for a living, were unable to do any work. The woman said, "we usually go and work in Sobhanbagh but now it is all flooded and we cannot earn any money." Another woman, who was still able to break bricks [although her place was slowly getting flooded], said that she was relying on the 3 takas she made per tokri (basket) to survive. Another man said, "we are slightly worse off but before the floods we were not much better off either. "A few women claimed that since their houses were completely submerged by the flood waters, the rent in the nearby bastis had risen, "Apa what will we do, pay rent of taka 900 or try and eat food to live?"

\footnotetext{
${ }^{4}$ Local three wheeler type of transport.
} 
Others stated, "we cannot pay 200 taka rent and also eat, and with no income what are we going to do?"

Some women complained that they were unable to continue their income earning activities such as selling vegetables, sugar cane, and selling clothes because prices had risen. "Apa, now a mishti kumra (pumpkin) costs 12 taka or more, 20 taka in some places, before we could buy mishti kumra for 4 or 5 taka...now how can we buy and how can we sell?" Another woman who was repaying an NGO loan stated, "we cannot even sell saris anymore, where is the money?" Most of the women complained that they were having difficulties repaying loans and resorted to borrowing from different people (loan sharks and relatives) to repay these loans. Thus, the consequence is further debt problems for the women and their families. It has been argued that the loss of one set of resources for the poor seriously affects the functioning of others, and disasters can send such families or particular members into a downward spiral, 'intensifying their burdens and decreasing the prospect of recovery' (8).

\section{Domestic Violence : "I can't ask him for money - he will beat me!"}

Owing to the existing taboos and shame associated with domestic violence, most women were reluctant to speak about domestic abuse. A few of the women viewed it as a 'private' family matter and thus felt disinclined to comment on incidents in their neighbourhood. Further, some women felt they deserved to be beaten, owing to their own behaviour, thus taking the blame on themselves. Some women, however, preferred to deny any knowledge of violence in their basti, perceiving it as undermining their community or basti 's reputation, "Not in our basti, we don't have problems like that. All our men are good. In the other bastis these things probably happen!" However, the study uncovered some incidents of domestic violence. In one of the slums visited, a group of women pushed a young girl, no more than 16 years of age forward and exclaimed, "look at her, look at her arm Apa, it is broken" [I looked to see a large bruise on her arm

and her face was considerably swollen]. She retorted, 'He beat me because I asked him for bazaar money, he hasn't bought anything for the last two days so I asked him for money to buy food and he beat me." 
The women explained that due to the recent flood, there was less money, and greater pressure on the husbands to provide for their families. "Apa, due to the frustration of being baykar (unemployed) they beat us!" Most of the women and men $^{5}$ agreed that the lack of work, the increasing uncertainties due to the floods, had led to increased tensions amongst family members, resulting in some incidents of domestic violence. Most of the women said that they felt vulnerable and angry but were unable to do anything regarding their situation. One woman narrated, 'I cannot ask him anything at all and if I do, he beats me.' A BRAC flood report (9), also found similar reported incidents of domestic violence in eight study areas ${ }^{6}$, of the worst flood affected areas of Dhaka city.

\section{Social Capital}

Nath describes how rural women in the course of their daily work meet, interact, and exchange news and information beyond the confinement of their household boundaries (10). Similarly, in urban areas, there tends to be an extensive network throughout each slum. Most households within the neighbourhood are generally linked through fictive or 'real' kin ties, and tend to rely on each other for social support. However, in a crisis situation, people tend to become displaced and dispersed. Thus, there is a break in the old network of existing bonds, as people may re-locate temporarily to shelters, abandon their homes, and move elsewhere. In addition, the burden of poverty and increasing uncertainty, result in individuals becoming very self absorbed, in their own and their family's survival.

There appeared to be no visible unity amongst the women or men residing in Shaheedertek or Bailtola slums. They were unable to mobilize any groups together and due to their own extreme poverty, were unable to look out for one another. However, a few individuals regularly informed the community about food relief being provided in particular localities. Although, it is quite feasible that at an invisible level some of the

\footnotetext{
${ }^{5}$ They were interviewed separately, to afford privacy and encourage discussion on the violence issue. 'Domestic violence was not reported in all of the eight areas, but there were reports of violence from at least one area by a number of women, who admitted that although their husbands beat them occasionally, the recent floods had exacerbated the situation.
} 
women and men provided each other with comfort and relief emotionally, if unable to materially. Surprisingly, the only area in which the women and men in the bastis of Shaheedertek, had visibly mobilized, was in the daily feeding of the Maulana ${ }^{7}$ at the basti masjid. "Apa we are taking turns feeding him, after all he is teaching our children prayers and the Quran. ${ }^{8}$ Nurul Amin (a local leader) has drawn up a list of the people who will feed the Maulana, so we all know who is feeding him on which particular day."

In the ShobujBagh area of Shibir Masjid and Mothertek, there appeared to be greater unity. Several hundred people were living in tran shibirs (empty construction sites turned into relief camps) in Mothertek. They had moved because they were no longer able to remain in their homes. In the tran shibirs, there was an organizing committee who had a list of all the families residing. The food items were passed onto members of the organising committee, who were in charge of distributing the food and relief items to all the families residing in the trans shibirs. In the slums of Shibir Masjid, families volunteered information on other members in the neighbourhood, so that no one missed out on flood relief goods. Others even volunteered to keep relief goods on behalf of families who were unavailable at the time. According to NGO staff, follow up visits revealed that most of the families no matter how desperate or poor, had always passed on the food items to the concerned family members, rather than keeping the food for themselves.

\footnotetext{
${ }^{7}$ Religious teacher.

${ }^{8}$ The holy book for Muslims.
} 


\section{Relief Assistance : Adequate Enough ?}

There appears to be a culture of 'universal dependence" existing amongst a majority of the urban poor. Most expected government and NGQs agencies to provide food supplies, clothing, money and general assistance during disasters. It has been argued that this mentality can lead to a type of apathy amongst the poor, who may hesitate to help themselves (2). Slum dwellers acknowledged assistance received from government, NGOs, and charity organizations. Many were, however, angry and held the view that they had received insufficient assistance from NGOs, as well as the government. A few individuals mentioned that relief operations were much better during the 1988 floods. They felt that the present distribution by the government in their slums had been misappropriated, while a few argued that since the basti populations had increased considerably in the last ten years, it was impossible for the 'NGOs and the government to feed everyone. '

\section{Conclusion}

The study highlighted some of the perceptions, needs and vulnerabilities of the urban poor. It revealed various social, cultural and economic issues which affect their lives, particularly during a crisis situation. Women and children are often the most vulnerable groups during disasters. The report illustrated the complete devastation in their lives, from extensive losses in material resources - home, bedding, and utensils, to greater uncertainty with employment, health, and access to basic services. Temporary relocations occasionally led to the breakdown of carefully built up social networks, increasing insecurity and uncertainty at unfamiliar shelters. Furthermore, greater liabilities were incurred as money was required for basic living costs. Existing resources become commercial commodities, with the poor paying for basic services such as water, and access to latrines, with rent prices increasing dramatically. For some of the poor, who were part of an NGO micro-credit group, being forced to repay loans during the floods, resulted in bigger debt problems. This creates a culture of hostility and alienation from

\footnotetext{
${ }^{9}$ Term borrowed from Alexander's paper on "Flood and Drought Perception: A Review and Comparative Cultural Perspective, 'In. Mir M Ali et al (eds) Bangladesh Floods: Views from Home and Abroad. Dhaka: University Press Limited.
} 
the particular NGO (6). In addition, NGOs appeared to be working separately in the affected areas. NGOs and the government could link up to work more effectively together during the floods, thus creating more efficient relief operations. 


\section{References}

1. Haque, C.E. Human Adjustments to River Bank Erosion Hazard in the Jamuna Floodplain, Bangladesh. Human Ecology, 1998. 16(4):421-37.

2. Alexander, D. E. Flood and Drought Perception: A Review and Comparative Cultural Perspective. In, Mir M Ali et al eds. Bangladesh Floods: Views from Home and Abroad, 1998. Dhaka: University Press Limited.

3. Haque and M.Q., Zaman. Coping with Riverbank Erosion Hazard and Displacement in Bangladesh; Survival Strategies and Adjustments. Disasters, 1989, 13 (4):300-14

4. Rashid, S., and Shahaduz Zaman. Are the Urban Poor More Vulnerable than their Rural Counterparts : What can BRAC's Urban Program Do for Them? (Draft BRAC report, unpublished). Dhaka, 1999: Bangladesh.

5. Rashid, S., and Michaud S. Female Adolescents and Ideologies of Honor, Shame, Purity and Pollution during the Floods, Dhaka, 1998. BRAC report.

6. Abdullah T.A. and Zeidenstein, S.A. Village Women of Bangladesh. Prospects for Change: A Study Prepared for the International Labour Office. Oxford, U.K, 1982: Pergamon Press.

7. Islam, Nazrul. The Urban Poor in Bangladesh. Centre for Urban Studies, Dhaka, 1996: Momin Offset Press, Bangladesh.

8. Wood. Security and Graduation: Working for a living in Dhaka Slums. Discourse, a journal of Policy Studies, 1998, vol 2, no 1, pp.26. Dhaka: Bangladesh.

9. BRAC Flood Study Team. A Quick Assessment Of Flood Losses and Post Flood Rehabilitation Needs in BRAC's Programme Areas. BRAC RED, Dhaka, 1998. Bangladesh.

10.Nath, J. Dynamics of Socio-economic Change and the Role and Status of Women in Natunpur: Case Study of a Bangladeshi Village. University of Dhaka, Bangladesh, 1986. $\mathrm{pp}$ - (dissertation). 